\title{
Single dose testosterone increases total cholesterol levels and induces the expression of HMG CoA Reductase
}

\author{
Nina Gårevik, Cristine Skogastierna, Anders Rane and Lena Ekström
}

\begin{abstract}
Background: Cholesterol is mainly synthesised in liver and the rate-limiting step is the reduction of 3-hydroxy3methylglutaryl coenzyme A (HMG-CoA) to mevalonate, a reaction catalysed by HMG-CoA reductase (HMGCR). There is a comprehensive body of evidence documenting that anabolic-androgenic steroids are associated with deleterious alterations of lipid profile. In this study we investigated whether a single dose of testosterone enanthate affects the cholesterol biosynthesis and the expression of HMGCR.
\end{abstract}

Methods: 39 healthy male volunteers were given 500 mg testosterone enanthate as single intramuscular dose of Testoviron ${ }^{\circledR}$-Depot. The total cholesterol levels prior to and two days after testosterone administration were analysed. Protein expression of HMGCR in whole blood was investigated by Western blotting. In order to study whether testosterone regulates the mRNA expression of HMGCR, in vitro studies were performed in a human liver cell-line (HepG2).

Results: The total cholesterol level was significantly increased 15\% two days after the testosterone injection ( $p=0.007$ ). This is the first time a perturbation in the lipoprotein profile is observed after only a single dose of testosterone. Moreover, the HMGCR mRNA and protein expression was induced by testosterone in vitro and in vivo, respectively.

Conclusion: Here we provide a molecular explanation how anabolic androgenic steroids may impact on the cholesterol homeostasis, i.e. via an increase of the HMGCR expression. Increasing knowledge and understanding of AAS induced side-effects is important in order to find measures for treatment and care of these abusers.

Keywords: Testosterone, Cholesterol, HMG CoA reductase

\section{Background}

Anabolic androgenic steroids (AAS) including testosterone, other endogenous androgenic hormones and synthetic substances structurally related to these compounds are the most frequently detected doping agents in the society and sports. The abuse of these agents for cosmetic purposes among non-competitive recreational body-builders and non-athletes is a considerable health concern. According to studies in Western societies the prevalence of abuse of anabolic androgenic steroids among high school and college students ranges from 1 to $5 \%[1-3]$.

\footnotetext{
* Correspondence: lena.ekstrom@ki.se Department of Laboratory Medicine, Division of Clinical Pharmacology, Karolinska Institutet, Karolinska University Hospital, SE-14186 Stockholm, Sweden
}

@ 2012 Gårevik et al; licensee BioMed Central Ltd. This is an Open Access article distributed under the terms of the Creative Commons Attribution License (http://creativecommons.org/licenses/by/2.0), which permits unrestricted use, distribution, and reproduction in any medium, provided the original work is properly cited.
There is a comprehensive body of evidence documenting that AAS induce various deleterious alterations of the lipoprotein profile. The most prominent changes include elevations of low density lipoprotein (LDL) and decreases of high density lipoprotein (HDL) [4-7]. The long-term consequences of these alterations are still unknown but it is possible that the perturbation of the lipid profile may be associated with an increase in risk of coronary artery disease.

Cholesterol is mainly synthesised in the liver and the rate-limiting step is the reduction of 3-hydroxy-3methylglutaryl coenzyme A (HMG-CoA) to mevalonate, a reaction catalysed by HMG-CoA reductase (HMGCR). Normally in mammalian cells the transcription of $H M G C R$ is suppressed by cholesterol derived from the internalization and degradation of LDL via the LDL 
receptor. Competitive inhibitors of the HMGCR by statins lead to induction of the expression of LDL receptors in the liver, which in turn increases the catabolism of plasma LDL and lowers the concentration of cholesterol in plasma. It is conceived that statins have a preventive effect on cardiovascular disease to a great extent by these mechanisms in several populations [8].

In this study we investigated whether a single dose of testosterone enanthate affects the cholesterol profile and the expression of HMGCR in healthy volunteers. The lipoprotein profile was analysed prior to, and two and fifteen days after administration of $500 \mathrm{mg}$ testosterone enanthate. The protein expression of HMGCR in whole blood was determined by Western blotting. Moreover, human liver cells (HepG2) were exposed to supra-physiological concentrations of testosterone enathate and the mRNA HMGCR level was quantified by real time analysis.

\section{Methods}

\section{Subjects and design}

Study subjects included 39 healthy volunteers originating from the study population described in detail elsewhere [9]. All participants were males at age 18-50 years, and gave informed consent consistent with the approval of the Ethics Review Board. The participants were given $500 \mathrm{mg}$ testosterone enanthate as a single intramuscular dose of Testoviron ${ }^{\circledR}$ - Depot (kindly provided by Schering Nordiska $\mathrm{AB}$, Solna) equivalent to $360 \mathrm{mg}$ testosterone. Blood and serum was collected prior to (day 0), 2 and 15 days after testosterone administration. All samples were collected between 07 and 11 am and were directly frozen at $-20^{\circ} \mathrm{c}$.Averse drug reactions (ADRs) were monitored from the time of screening until day 15 after administration of testosterone. The study was conducted according to the Helsinki declaration and the ICH Harmonised Tripartite Guideline for Good Clinical Practice.

\section{Western blotting}

The level of the HMGCR enzyme in whole blood samples was examined by Western blotring analysis. Frozen whole blood samples were available from 24 subjects of the 39 individuals included in the study. The blood samples were mixed 1:12 with $2 \mathrm{mM}$ EDTA and complete protease inhibitor cocktail (cat no 11697498001 Roche) and freeze-thawed three times. The hemolysates were separated on $12 \%$ polyacrylamide gel, electrotransferred onto Hybond-C extra membrane (GE healthcare), blocked overnight in high salt base buffer (HSB) $(50 \mathrm{mM}$ Tris- $\mathrm{HCl} / 500$ $\mathrm{mM} \mathrm{NaCl}, \mathrm{pH} 7.5), 2 \%$ dried milk, $1 \% \mathrm{BSA}$ and incubated for two hours with 1:400 dilution of rabbit anti-HMGCR antibody (Santa Cruz Biotechnology). Membranes were washed in HSBT (HSB with $0.05 \%$ Tween) and incubated for 1 hour with 1:2500 horseradish peroxidise-linked mouse anti-rabbit immunoglobulin antibody (Promega, WI, USA). Detection of the protein bands was carried out using ECL Plus Western Blotting Detection System kit (GE healthcare, Uppsala, Sweden) and quantified by densitometry using BioRad Quantity One1 (version 4.1 software). A standard curve with increasing concentration of liver microsomes was included on each gel. The HMGCR expression in whole blood was normalized against the total protein level as was determined by Lowry [10].

\section{Cell culture}

HepG2 cells were cultured in MEM supplemented with $5 \%$ FCS, $1 \%$ penicillin/streptomycin, $1 \%$ L-glutamine and maintained in humidified atmosphere at $37^{\circ} \mathrm{C}$ and $5 \%$ $\mathrm{CO}_{2}$. Prior to testosterone treatment the HepG2 cells were split and plated in 6-well plates and pre-incubated for 3 days. Testosterone enanthate was diluted in ethanol and added to the cells $(1 \mu \mathrm{M})$ for $2-48$ hours. The nontreated controls were incubated with vehicle only. The experiments were performed in four independent experiments. For RNA extraction the cells were harvested with Trizol (Invitrogen, UK) and kept at $-80^{\circ} \mathrm{C}$ until analysis.

\section{RNA extraction and cDNA}

Total RNA extraction was performed using $0.5 \mathrm{ml}$ Trizol per well according to manufacturer's instructions. RNA $(0.5 \mu \mathrm{g})$ was reverse transcribed into cDNA with hexamer primer using first-strand cDNA synthesis kit (Amersham Biosciences, NJ, USA) according to the manufacturer's protocol and diluted $10 \mathrm{X}$ in sterile water.

\section{Real time PCR}

The mRNA level of HMGCR in testosterone treated HepG2 cells was determined by real-time PCR. Betaactin (PN 4326315E, Applied Biosystems, Foster City, $\mathrm{CA})$ was chosen as an endogenous housekeeping control gene. Quantitative real-time PCR was performed using the 7500 Fast system, Applied Biosystems. Reaction mixtures contained Taqman reaction mix (Applied Biosystems), HMGCR Taqman Assay mix (Hs01103000_m1, Applied Biosystems), $4 \mu \mathrm{l}$ cDNA template in a total volume of $20 \mu \mathrm{l}$. Thermal cycling conditions included activation at $95^{\circ} \mathrm{C}(10 \mathrm{~min})$ followed by 40 cycles each of denaturation at $95^{\circ} \mathrm{C}(15 \mathrm{sec})$ and annealing/elongation at $60^{\circ} \mathrm{C}(1 \mathrm{~min})$. Each reaction was performed in triplicates and no-template controls were included in each experiment. The untreated sample was employed as a calibrator and the $\Delta \Delta \mathrm{CT}$-formula was used as described previously [11]. The gene expression was quantified as the yield of the target gene relative to that of Beta-actin gene. 


\section{Serum analysis}

Serum total cholesterol, HDL, LDLD, alanine transaminase (ALAT) and aspartate transaminase (ASAT) were determined by routine analyses at the division of clinical chemistry, Karolinska University Hospital. Total testosterone levels in serum prior to and after testosterone administration had been measured by GCMS in a previous study [12]

\section{Data analysis}

Statistical analyses were performed using GraphPad Prism software 4.03 (GraphPad, San Diego, CA). The increase in cholesterol levels after testosterone injection was compared using ANOVA. The protein expression of HMGCR prior to and after testosterone administration was compared using Wilcoxon test whereas Mann-Whitney test was used for comparison of HMGCR mRNA levels between testosterone treated and non-treated HepG2 cells.

\section{Results}

\section{Cholesterol levels}

Total cholesterol level increased on day two (mean 4.87 $\mathrm{mmol} / \mathrm{L}+/ \mathrm{SD} 0.25$ ) compared to day 0 (mean 4.23 $\mathrm{mmol} / \mathrm{L}+/-\mathrm{SD} 0.27)(\mathrm{p}=0.007$; ANOVA) (Figure 1). On day 15 the total cholesterol level was back to baseline (mean $4.23+/-$ SD 0.14). There was no significant difference in HDL, LDLD or VDL between day 0 and day 2 (data not shown).

A correlation analysis demonstrates that the increase in cholesterol levels was significantly correlated to the total testosterone levels on day $2\left(r^{2}=0.14 p=0.02\right.$; Spearman's rank correlation test). There were no alterations in the liver function biomarkers ALAT and ASAT.

\section{HMGCR expression in whole blood}

The increase in cholesterol level prompted us to investigate the expression of the main enzyme involved in the cholesterol synthesis. The protein expression of HMGCR, the rate limiting enzyme in the cholesterol synthesis, was investigated by Western blotting in whole blood from the subjects prior to, and two days after testosterone administration. In $80 \%$ of the individuals the HMGCR expression was increased 2 days after the administration of testosterone (Figure 2). In the whole group, there was a significant increase in HMGCR expression on day two compared to day 0 ( $\mathrm{p}=0.03$; Mann Whitney test).

\section{HMGCR mRNA expression in HepG2 cells}

Since testosterone induces HMGCR expression in vivo, we investigated whether it would also affect the mRNA expression of HMGCR in vitro. HepG2 cells were exposed to testosterone enanthate $(1 \mathrm{uM})$ for $2-48$ hours. The gene expression of HMGCR was 1.8 fold higher after 2 hours testosterone treatment $(\mathrm{p}<0.001$;

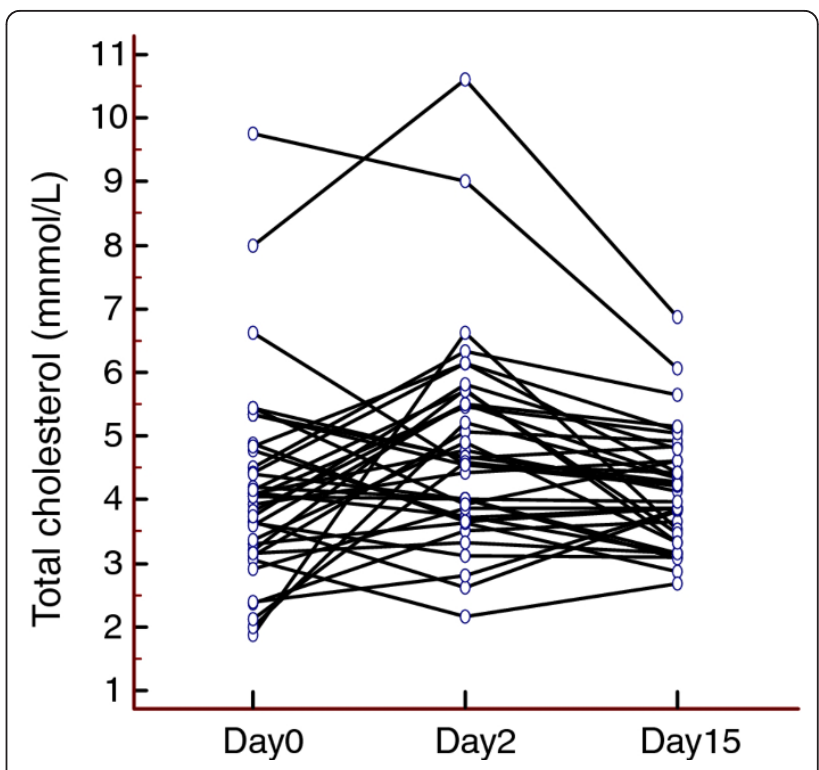

Figure 1 The change in total cholesterol levels on day 0 (prior to testosterone administration), $\mathbf{2}$ and $\mathbf{1 5}$ days after testosterone administration. The mean total cholesterol level was significantly higher 2 days after testosterone administration as compared to on day 0 ( $p=0.007$; ANOVA). 15 days after testosterone administration the total cholesterol level was back to baseline.

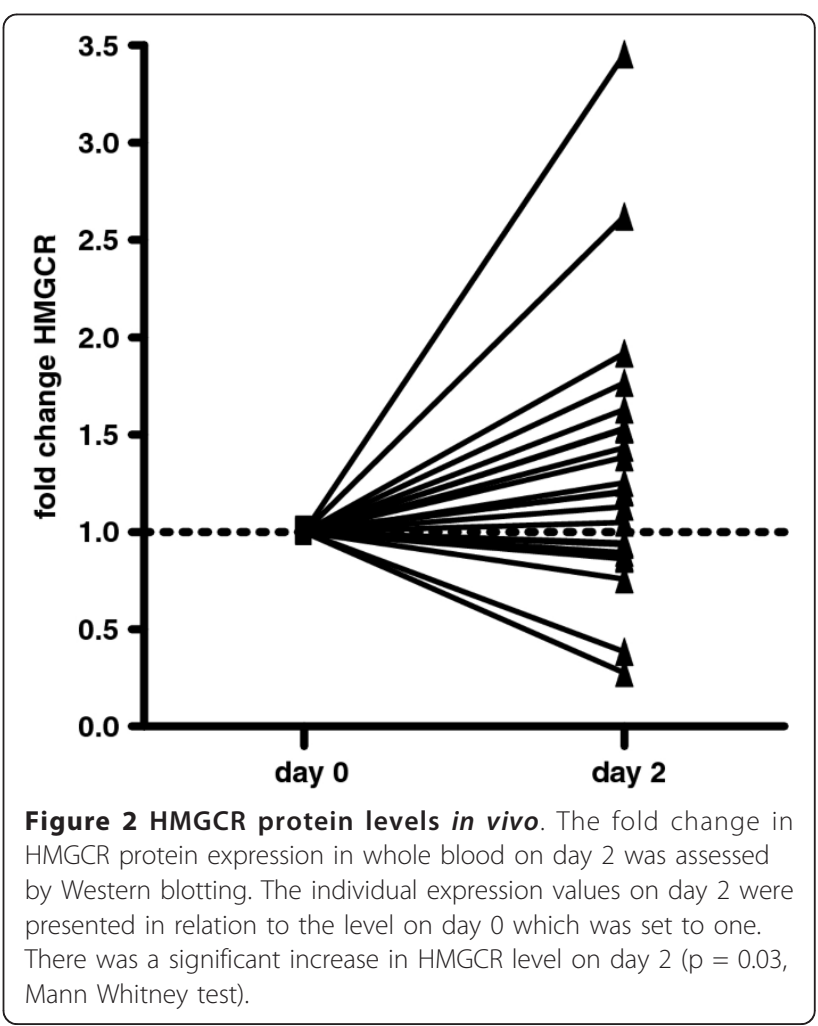


Mann Whitney test (Figure 3). A significant 0.8 fold decrease in HMGCR mRNA was observed after 24 hours $(\mathrm{p}=0.047)$. After 48 hours the mRNA levels were back to basal level.

\section{Discussion}

Even though accumulating evidence indicates that testosterone may have adverse effect on the lipoprotein profile and cardiovascular health, this is, to the best of our knowledge, the first time an increase in total cholesterol level has been observed after only one single dose of testosterone. 15 days after the testosterone administration the cholesterol levels in the volunteers was back to baseline levels.

Numerous reports on the effects of AAS on lipoproteins in humans have been published in the last 25 years. To a large extent the results of these studies present consistent results, i.e. AAS cause a marked depression in serum HDL and an elevation in LDL (as reviewed by [13] and [14]). However, for the effect on total cholesterol levels the results are conflicting. Some studies have found that repeated supra-physiologic doses of AAS is associated with an increase in total cholesterol levels $[15,16]$, whereas others have failed to find such an association $[5,6]$. The reason for the discrepancy observed in the effect on total cholesterol after AAS administration may be the different study designs used, sampling time, type of AAS used, administration route etc. However, most importantly, these studies all concerned subjects with multiple doses or chronic use of AAS.

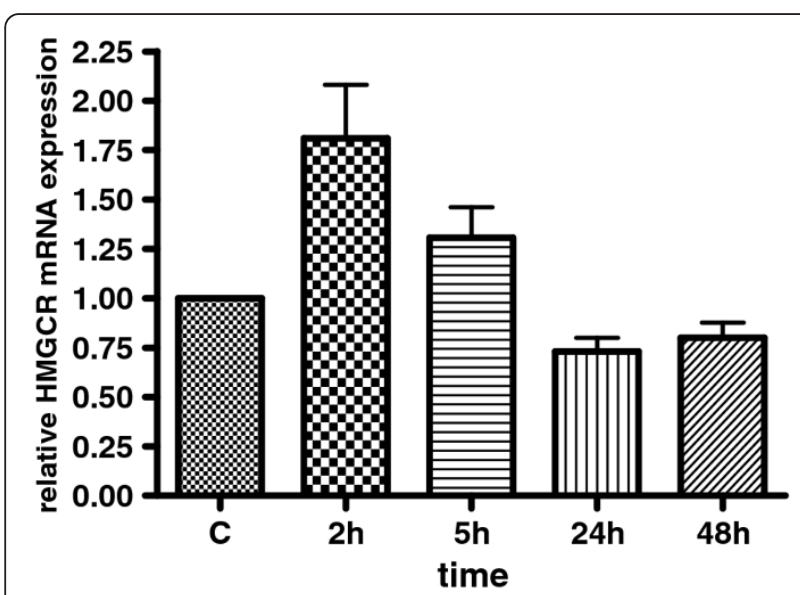

Figure 3 HMGCR mRNA levels in vitro. The effect of testosterone enanthate on HMGCR mRNA levels in HepG2 cells was determined at different time points. Cells were incubated with testosterone enanthate or vehicle $(C=$ control set as 1$)$ and total RNA was extracted, reverse transcribed and subjected to real-time PCR. Measurements were performed in triplicates and data are presented as means \pm SD $(N=4)$. There was a significant increase in HMGCR mRNA expression 2 hours after testosterone exposure $(p<0.001$; Mann Whitney test), whereas after 24 hours the levels was significant lower $(p=0.047)$ as compared to the controls.
The baseline serum testosterone concentration in our study population was $5 \mathrm{ng} / \mathrm{ml}$ [12] which is the same as has been seen in other study groups similar in respect of age, gender, ethnicity [17]. Two days after testosterone administration the serum testosterone level has increased by $200 \%$ [12]. Here we show that circulatory concentration of total testosterone was significantly associated with the increase in cholesterol levels on day 2. No toxic effect on liver function, as assessed by ALAT and ASAT, was found indicating that the increase in total cholesterol observed is directly associated with the administration of testosterone and not an artificial effect of the injection, i.e. stress or impact on the liver function.

The synthesis of cholesterol is dependent on the activity of HMGCR, and we therefore investigated if testosterone could affect the expression of this enzyme. Here we show for the first time that a supra-physiological dose of testosterone induces the expression of HMGCR in vivo in healthy volunteers. These observations were supported by the results from the experiments with HepG2 cells exposed to $1 \mu \mathrm{M}$ testosterone. This concentration is in the range of the levels achieved after administration of testosterone to the volunteers [12], and yielded a marked induction of the transcription of the HMGCR gene. Further support for this testosterone effect is provided from experiments in castrated mice and male SpragueDawley rats in which 14 days administration of AAS (testosterone and nandrolone) led to an up-regulation of meibomian and adrenal gene expression of HMGCR, respectively $[18,19]$. The mechanisms for the androgen induced up-regulation of HMGCR transcription as well as the physiological consequences have not been investigated and needs to be further elucidated. High cholesterol levels are known to exert a negative feedback on the cholesterol synthesis on a transcriptional level $[20,21]$. This may explain the time dependent response observed in our HepG2 experiments, i.e. the HMGCR mRNA expression was normalized or even down-regulated 24 hours after testosterone treatment.

Other molecular mechanisms behind the unfavourable effects of AAS on the lipoprotein profile have not been well investigated. It is believed that AAS exert some of their influence on the cholesterol profile by inducing the HDL-catabolising enzyme hepatic triglyceride lipase (HTGL) synthesis in the liver [5]. A 143-232\% increase of HTGL activity has been described during AAS abuse [4]. Here we provide an additional molecular explanation how AAS may impact on the cholesterol homeostasis, i.e. via an increase of the HMGCR expression. Further studies may provide yet other explanations behind the lipid profile perturbation observed as a result of AAS abuse.

AAS are the most commonly used doping agents in athletes (http://www.wada-ama.org). However, the abuse 
of AAS is not limited to competitive sports, but has spread to sport amateurs and non-athletes and is considered a serious concern in the society $[2,22]$. It is therefore urgent to study and establish the awareness of the adverse effects caused by AAS. Here we provide scientific evidence that a supra-physiological dose of testosterone may have adverse effects on the cholesterol metabolism. Our setting is, however, very different from the situation for the illicit users that typically take AAS in repeated courses known as "cycles", each lasting several weeks to several months. One might suspect that the HMGCR expression will rapidly increase after each dose, keeping the HMGCR protein expression and cholesterol metabolism elevated continuously during the "cycles".

Some limitations of our study need to be addressed. Using whole blood as surrogate model for HMGCR expression may not reflect the expression profile in the liver. Nevertheless, blood is a natural surrogate organ in the absence of availability of liver biopsies. It is to be noted that HMGCR and its main important transcription factors, i.e. SREBP-2 are highly abundant in the blood cells further supporting that whole blood may be used for expression analysis. Another limitation is that we only have the cholesterol profile in our study participants. The inclusion of cholesterol activity biomarkers such as lathosterol would further support that the administration of supra-physiological doses of testosterone disturb the cholesterol metabolism in vivo. Unfortunately our study design did not permit further analysis of additional biomarkers.

\section{Conclusions}

In conclusion, we have shown that already one single dose of testosterone enanthate increases the serum total cholesterol level. This immediate response to AAS is a cause for concern and signals that the lipid metabolic perturbation is a rapid response and warrants close follow-up of the cardiovascular risk factors that may appear later in life in abusers. There are many cases described in the literature on such adverse events in heavy abusers of AAS. Our findings demonstrate that such effects may occur also in subjects with moderate, intermittent, or temporary abuse of AAS. Therefore, given our findings, public efforts should be centered on primary prevention.

\section{Acknowledgements}

The technical assistance of Birgitta Ask is gratefully acknowledged. This study was supported by the World Anti Doping Agency (WADA), Swedish National Centre for Research in Sports, and the Stockholm County Council.

\section{Authors' contributions}

LE and AR planned, designed and wrote the study protocol for the in vivo study. CS planned and performed the cell culture analysis. LE and NG interpreted the data. NG performed the statistical analysis and managed the sample collection. LE wrote the first draft of the manuscript. All authors contributed to and have approved the final manuscript.

\section{Competing interests}

The authors declare that they have no competing interests.

Received: 7 November 2011 Accepted: 20 March 2012

Published: 20 March 2012

\section{References}

1. Kanayama G, Brower KJ, Wood RI, Hudson JI, Pope HG Jr: Anabolicandrogenic steroid dependence: an emerging disorder. Addiction 2009, 104:1966-1978.

2. Sjoqvist F, Garle M, Rane A: Use of doping agents, particularly anabolic steroids, in sports and society. Lancet 2008, 371:1872-1882.

3. Eklof AC, Thurelius AM, Garle M, Rane A, Sjoqvist F: The anti-doping hotline, a means to capture the abuse of doping agents in the Swedish society and a new service function in clinical pharmacology. Eur J Clin Pharmacol 2003, 59:571-577.

4. Glazer $\mathrm{G}$ : Atherogenic effects of anabolic steroids on serum lipid levels. A literature review. Arch Intern Med 1991, 151:1925-1933.

5. Kouri EM, Pope HG Jr: Oliva PS: Changes in lipoprotein-lipid levels in normal men following administration of increasing doses of testosterone cypionate. Clin J Sport Med 1996, 6:152-157.

6. Hartgens F, Rietjens G, Keizer HA, Kuipers H, Wolffenbuttel BH: Effects of androgenic-anabolic steroids on apolipoproteins and lipoprotein (a). $\mathrm{Br} J$ Sports Med 2004, 38:253-259.

7. Kuipers H, Wijnen JA, Hartgens F, Willems SM: Influence of anabolic steroids on body composition, blood pressure, lipid profile and liver functions in body builders. Int J Sports Med 1991, 12:413-418.

8. Lardizabal JA, Deedwania P: Lipid-lowering therapy with statins for the primary and secondary prevention of cardiovascular disease. Cardio/ Clin 2011, 29:87-103.

9. Schulze JJ, Lundmark J, Garle M, Skilving I, Ekstrom L, Rane A: Doping test results dependent on genotype of uridine diphospho-glucuronosyl transferase $2 \mathrm{~B} 17$, the major enzyme for testosterone glucuronidation. $J$ Clin Endocrinol Metab 2008, 93:2500-2506.

10. Lowry OH, Rosebrough NJ, Farr AL, Randall RJ: Protein measurement with the Folin phenol reagent. J Biol Chem 1951, 193:265-275.

11. Livak KJ, Schmittgen TD: Analysis of relative gene expression data using real-time quantitative PCR and the 2(-Delta Delta C(T)) Method. Methods 2001, 25:402-408.

12. Ekstrom L, Schulze JJ, Guillemette C, Belanger A, Rane A: Bioavailability of testosterone enanthate dependent on genetic variation in the phosphodiesterase 7B but not on the uridine $5^{\prime}$-diphosphoglucuronosyltransferase (UGT2B17) gene. Pharmacogenet Genomics 2011 21:325-332.

13. Vanberg P, Atar D: Androgenic anabolic steroid abuse and the cardiovascular system. In Doping in Sports - Handbook of Experimental Pharmacology 195. Edited by: Detlef T. Heidelberg: Springer-Verlag; 2010:411-457.

14. Hartgens F, Kuipers $\mathrm{H}$ : Effects of androgenic-anabolic steroids in athletes. Sports Med 2004, 34:513-554.

15. Hurley BF, Seals DR, Hagberg JM, Goldberg AC, Ostrove SM, Holloszy JO, Wiest WG, Goldberg AP: High-density-lipoprotein cholesterol in bodybuilders $v$ power lifters. Negative effects of androgen use. Jama 1984, 252:507-513

16. Ansell JE, Tiarks C, Fairchild VK: Coagulation abnormalities associated with the use of anabolic steroids. Am Heart J 1993, 125:367-371.

17. Simon D, Nahoul K, Charles M A: Androgens and the Aging Male New York: Parthenon Publishing; 1996

18. Schirra F, Richards SM, Liu M, Suzuki T, Yamagami H, Sullivan DA: Androgen regulation of lipogenic pathways in the mouse meibomian gland. Exp Eye Res 2006, 83:291-296.

19. Alsio J, Birgner C, Bjorkblom L, Isaksson P, Bergstrom L, Schioth HB, Lindblom J: Impact of nandrolone decanoate on gene expression in endocrine systems related to the adverse effects of anabolic androgenic steroids. Basic Clin Pharmacol Toxicol 2009, 105:307-314.

20. Horton JD, Goldstein JL, Brown MS: SREBPs: activators of the complete program of cholesterol and fatty acid synthesis in the liver. $J$ Clin Invest 2002, 109:1125-1131. 
21. Nakanishi M, Goldstein JL, Brown MS: Multivalent control of 3-hydroxy-3methylglutaryl coenzyme A reductase. Mevalonate-derived product inhibits translation of mRNA and accelerates degradation of enzyme. J Biol Chem 1988, 263:8929-8937.

22. Melnik BC: Androgen abuse in the community. Curr Opin Endocrinol Diabetes Obes 2009, 16:218-223.

doi:10.1186/1747-597X-7-12

Cite this article as: Gårevik et al:: Single dose testosterone increases total cholesterol levels and induces the expression of HMG CoA

Reductase. Substance Abuse Treatment, Prevention, and Policy 2012 7:12.

Submit your next manuscript to BioMed Central and take full advantage of:

- Convenient online submission

- Thorough peer review

- No space constraints or color figure charges

- Immediate publication on acceptance

- Inclusion in PubMed, CAS, Scopus and Google Scholar

- Research which is freely available for redistribution

Submit your manuscript at www.biomedcentral.com/submit 